\title{
Dyslexia-friendly fonts Using Open Dyslexic to increase exhibit access
}

I: two recent exhibits at Cushing Memorial Library and Archives, Texas A\&M University, we made the decision to try to increase the level of access to both the objects and their explanatory texts, for patrons who suffer from dyslexia. One of our then-student workers, herself dyslexic, proposed to library administration that our exhibits would be more welcoming if we had a way to provide for dyslexics and ease their exhibit experience. We agreed that this was an excellent idea and, in fact, kicked ourselves for not having thought of it earlier. We present this small summary of our experience in order that other institutions might see it as a useful case study for adapting their own exhibits or public programming to meet the needs of dyslexic patrons and visitors.

\section{Open Dyslexic}

The International Dyslexia Association defines dyslexia as "a specific learning disability that is neurobiological in origin. It is characterized by difficulties with accurate and/or fluent word recognition and by poor spelling and decoding abilities. These difficulties typically result from a deficiency in the phonological component of language that is often unexpected in relation to other cognitive abilities and the provision of effective classroom instruction. Secondary consequences may include problems in reading comprehension and reduced reading experience that can impede growth of vocabulary and background knowledge."
Symptoms of dyslexia can include problems with spelling or letter order, problems articulating certain sounds and words, difficulties distinguishing different sounds in words or letters, or viewing words backwards.

Of course, this means that exhibit literature-such as catalogs, explanatory labels, or recorded commentary-can be difficult, even frustrating, to read for dyslexics. As far as written material goes, a relatively easy solution does exist for this problem. Several groups have designed fonts with the intention of making the text easier or less stressful for a dyslexic individual to read. Some of these fonts can be purchased from the creators, while others are free to use. For Cushing's purposes, we decided to use the font Open Dyslexic (OD).

OD is an open source font that was created to increase readability of texts for individuals with dyslexia. The letters of the font "have heavy weighted bottoms to indicate direction," enabling the reader "to quickly figure out which part of the letter is down which aids in recognizing the correct letter." ${ }^{2}$ The weighted design and unique shapes of the letters helps prevent the dyslexic reader's mind from moving and flipping the letters.

Sierra Laddusaw is map librarian, email: sladdusaw@ library.tamu.edu, and Jeremy Brett is associate professor, Cushing Memorial Library and Archives, email: jwbrett@library.tamu.edu, at Texas A\&M University

๑ 2019 Sierra Laddusaw and Jeremy Brett 

sons. It is widely used, and it is accepted as an option for a number of different platforms, such as Wikipedia, Amazon Kindle Paperwhite, and Kobo eReader. This suggested to us that there is clearly a demand for the font, therefore it was most likely useful to our patron communities. As a public university, we are always looking to be cost-effective, so the fact that OD is opensource was not lost on us. We did look at other dyslexicintervention typefaces, most notably the Dutch product Dyslexie, but in the end, OD's opensource nature and our student's own positive experience with the font made it our clear choice.

Previous literature has been published on the use of

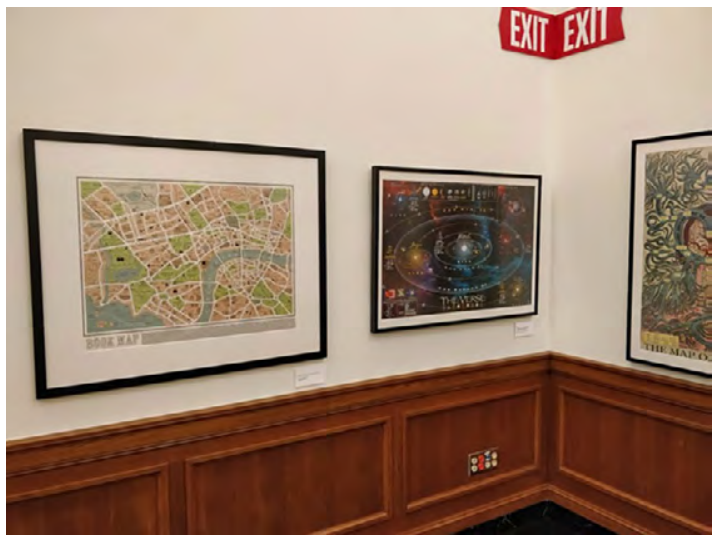

One corner of the "Worlds Imagined" exhibit.
We chose this particular font for several rea-

and roman font types increased significantly the reading performance" and that fonts designed specifically for dyslexic readers, like OD, did not show increased or decreased readability when compared to standard sans serif fonts. ${ }^{4}$

Another study also found that readability is affected by font choice, but found also that page layout and design had an impact on the readability of the text. ${ }^{5}$ Studies reported that dyslexic readers requested or may have found the use of fonts like OD more useful if they had time to become familiar with them. ${ }^{6,7}$

Several archives and museums provide guidelines or have statements on accessible design. The International Federation of Library Associations and Institutions (IFLA) created alternative fonts for individuals with dyslexia, but little has been written about the use of alternative fonts in archive and museum environments to increase the accessibility of an exhibit. This seems to be in keeping with the general atmosphere of concern with the needs of the visually impaired taking precedence (for example, the 1990 Americans with Disabilities Act includes "Standards for Accessible Design" that outline specific guidelines for sign typography in public spaces, but nothing in these standards specifically make provision for the needs of cognitive disorders like dyslexia.)

The majority of the available research focuses on the use of alternative fonts in classroom and educational settings. In one case researchers found the use of the OD font did not show a marked improvement in the number of errors made by a dyslexic reader, however the readers reported the OD font was easier for them to read, leading to less reading anxiety. ${ }^{3} \mathrm{~A}$ second study found that font choice does have an impact on readability for individuals with dyslexia, fonts that are "sans serif, monospaced, a guide for providing services to individuals with dyslexia. Section 5 of IFLA's Guidelines covers recommendations for text based content, including guidance on font type, size, and color. One of the fonts IFLA recommends is OD. ${ }^{8}$ The Smithsonian produced a set a guidelines for accessibility that includes a section on text, they recommend sans serif fonts and provide the following characteristics of an accessible font:

- proportions that contribute to legibility

- a clear extension for lowercase b, d, g, $\mathrm{h}, \mathrm{j}, \mathrm{k}, \mathrm{l}, \mathrm{p}, \mathrm{q}, \mathrm{t}$, and $\mathrm{y}$

- easily legible numbers (e.g., distinguishable 5,6 , and 8$)^{9}$

The Canadian Museum for Human Rights uses fonts for their exhibits that are "chosen for typographic elements, such as anatomy and letter proportions" and design layouts for text where paragraph alignment, type placement, and font size are all taken into account. ${ }^{10}$ Booklets printed in dyslexic-friendly fonts are made available by the Amon Carter Museum of 
American Art in their permanent painting and sculpture collections. ${ }^{11}$

\section{What we did and results}

Two exhibits at Cushing Library have incorporated OD into their exhibition material; first "Shifting Frontiers: Texas from Spain to Space, followed a few months later by "Worlds Imagined: The Maps of Imaginary Places Collection." How-

The title page of the exhibit guide in Open Dyslexic text format.

ever, we found

that the Worlds Imagined exhibit would prove to be a more optimal testbed for using OD material because it is a relatively text-free platform. Item labels for exhibit materials were kept to a bare minimum: the title of the map, the date of composition, the name of the cartographer(s), and the title, author, and date of the source material. No explanatory text or contextual information was included on exhibit labels, because the curators wanted to move away from

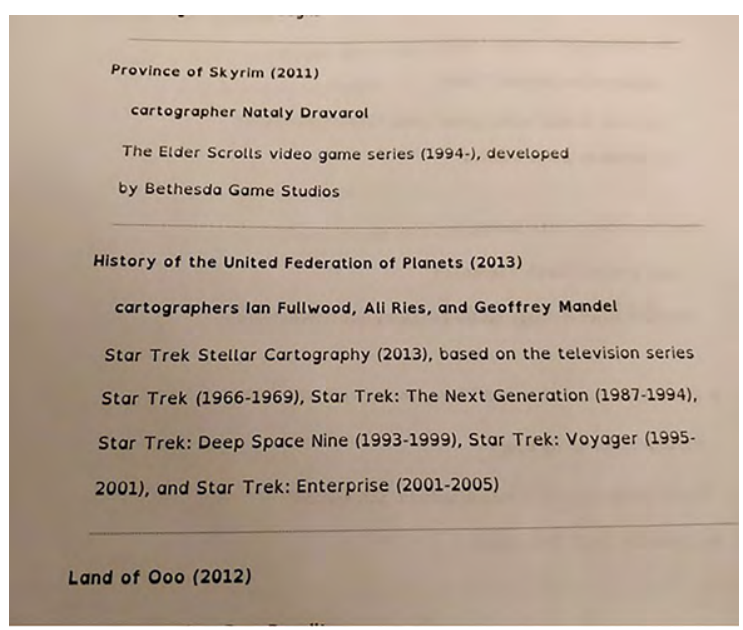

A page from the Open Dyslexic exhibit guide. columns to six to nine words; ensure that text columns are separated by plenty of space; and, especially important for loquacious academics, avoid long sentences!"12

As a result, people wanting to read the labels in OD needed only to consult a brief, 20-page guide to get the same information as nondyslexic visitors. The guide was structured to let readers follow the exhibit in a counterclockwise route along the outside walls, then moving inwards in a spiral along interior standing walls, and finishing by moving down a gallery hall at the far end of the exhibit hall (again, counterclockwise) There are two copies of the guide available at the exhibit entrance, and visitors may take them around the exhibit as they go.

Using a handheld guide separate from the wall placards was not an ideal solution, we recognize, but given our available resources, space, previous Cushing exhibits that tended towards text-heavy placards. The decision to limit text in the placards and to generally reduce text in the exhibit catalog, we believe, benefits dyslexic visitors.

As Stanford University student Adeana McNicholl noted in a 2015 blog post, "Even text layout can impact people with dyslexia—some tips for creating dyslexic-friendly texts are to divide texts into several paragraphs; limit text and logistics, it was our most viable option. We did not want to crowd the walls with duplicate placards in different fonts. In addition, as noted above, people with dyslexia often benefit from particular text formats, that, in our case, did not fit our chosen aesthetic for the placards.

Text providing more information about the maps (or, more specifically, the lands that the maps describe) was confined to the exhibit catalog. Unfortunately, the personnel and time 
requirements to produce two copies of the catalog, combined with the high costs of printing dual runs of catalogs, prevented the creation of an entire OD-based catalog. Were Cushing to do this all over again, the curators would have tried to arrange for the required production time to design the layout of OD-specific catalogs and factored in the printing costs for a small number of OD-specific catalogs.

However, despite this limitation, the results of adding OD text to the exhibit have been positive. Although Cushing has not made any systematic attempts to gauge popular response to the OD material, anecdotal evidence reveals that the material has been well received by visitors. Several people have expressed their gratitude in the exhibit comment book for this service, and Reading Room staff have observed a number of visitors using the guides as they explore the exhibit. One was, to quote a staff member, "almost in tears using it, very happy, grinning ear to ear." Several visitors have spoken to Reading Room staff to let them know their appreciation for the guides.

In the end, we have been very pleased with the outcome of our OD exhibit experiment. The positive patron response has been gratifying, and it has made us, as exhibit curators, much more aware of the needs of patrons with cognitive disorders. We intend to use the experiences gained in putting together our last two exhibits going forward, and are working to ensure that future exhibits provide optimal levels of access for dyslexics and other patrons suffering from cognitive disorders.

The authors thank Katelyn Balkum for her work on introducing Open Dyslexic at Cushing Memorial Library and Archives.

\section{Notes}

1. "Definition of Dyslexia," International Dyslexia Association, November 12, 2002, https://dyslexiaida.org/definition-of-dyslexia/.

2. "About," Open Dyslexic, accessed February 7, 2018, https://Open Dyslexic.org/about-2/.

3. Pavel Zikl, Iva Košek Bartošová, Kate ina Josefová Víšková, Klára Havlí ková, Alice Ku írková, Jolana Navrátilová, and Barbora Zetková, "The Possibilities of ICT Use for
Compensation of Difficulties with Reading in Pupils with Dyslexia," Procedia-Social and Behavioral Science, 176 (2015): 915-922, https:// doi.org/10.1016/j.sbspro.2015.01.558.

4. Luz Rello and Ricardo Baeza-Yates, "Good fonts for dyslexia," paper presented at the 15th Annual ACM SIGACCESS International Conference on Computers and Accessibility in Bellevue, Washington, October 2013.

5. Maya Grigorovish-Barsky, "The Effects of Fonts on Reading Performance for Those with Dyslexia: A Quasi-Experimental Study," accessed February 7, 2018, https:// goed.american.edu/img/userFiles/2713_77676 _Research_Project_-_Final_for_Portfolio.pdf.

6. Ibid., Zikl, et.al., "The Possibilities of ICT Use for Compensation of Difficulties with Reading in Pupils with Dyslexia," 2015.

7. Grigorovish-Barsky. "The Effects of Fonts on Reading Performance for Those with Dyslexia: A Quasi-Experimental Study," 2013.

8. Library Services to People with Special Needs and Libraries Serving Persons with Print Disabilities, "IFLA Guidelines for Library Services to Persons with Dyslexia," International Federation of Library Associations and Institutions, accessed February 7, 2018, https://www.ifla.org/files/assets/lsn /publications/guidelines-for-library-services -to-persons-with-dyslexia_2014.pdf.

9. Smithsonian Accessibility Program, "Smithsonian Guidelines for Accessible Exhibition Design, accessed February 7, 2018, http:// accessible.si.edu/pdf/Smithsonian\%20Guidelines\%20for\%20accessible\%20design.pdf.

10. "Inclusive Design and Accessibility," Canadian Museum for Human Rights, accessed February 7, 2018, https://humanrights.ca/visit/ inclusive-design-and-accessibility.

11. "Accessibility," Amon Carter Museum of American Art, accessed February 7, 2018, www.cartermuseum.org/visit /accessibility.

12. Adeana McNicholl, "Student Perspective: Accessibility in Museum Exhibit Design," Stanford University Archaeology Collections, accessed June 15, 2018, https:// suac.stanford.edu/news/student-perspective -accessibility-museum-exhibit-design $\mathbf{2}$ 